\title{
Posterior pituitary neurohormonal disturbances in schizophrenia and role of oxytocin in treatment - need for more short- and long-term studies
}

This article was published in the following Dove Press journal:

Neuropsychiatric Disease and Treatment

\author{
Owais Gul' \\ Saqib Gul ${ }^{2}$ \\ Abdul Aziz Godil ${ }^{3}$ \\ 'Department of Medicine, Dow \\ Medical College, Dow University of \\ Health Sciences, Karachi, Pakistan; \\ ${ }^{2}$ Department of Medicine, Hamdard \\ University, Karachi, Pakistan; \\ ${ }^{3}$ Department of Medicine, Jinnah \\ Medical and Dental College, Karachi, \\ Pakistan
}

\section{Dear editor}

We read with great interest the recently published article "Atrial natriuretic peptide and posterior pituitary neurohormone changes in patients with acute schizophrenia" by Guzel et al. ${ }^{1}$ The study results are vital in understanding the variations among the levels of posterior pituitary neurohormones in patients with acute schizophrenia and seem to be of great value for future therapeutic modifications of the disease.

This cross-sectional study revealed the posterior pituitary neurohormone changes in acute schizophrenia patients. The researchers used two groups. One comprised schizophrenia patients with an acute episode, and another comprised healthy individuals. The authors used Positive and Negative Syndrome Scale (PANSS), Clinical Global Impression (CGI) scale and General Assessment of Functioning (GAF) scale for the assessment of the symptoms and did serum analysis to find the correlation among the levels of oxytocin (OXT), arginine-vasopressin (AVP) and atrial natriuretic peptide (ANP). The study showed a negative correlation between OXT levels and PANSS and CGI scores while a positive correlation was found between OXT levels and GAF score. The study depicted that the patients with acute schizophrenia have significantly low levels of OXT and significantly high levels of AVP. ANP levels were also found to be low, but a significant clinical correlation was not found. The authors thus concluded that OXT, in particular, is associated with decreased severity of schizophrenia and may improve functionality of these patients.

Many studies have been conducted in the past regarding the use of OXT in the treatment of social deficits in schizophrenia patients. ${ }^{2,3}$ Earlier, a small trial conducted in 2014 showed improvements in social deficits following 6-week intranasal (IN) OXT therapy. ${ }^{2}$ Later, another study in 2015 demonstrated the positive effect of single dose of OXT in a small group of patients. ${ }^{3}$ However, recent developments in this regard are revealing poor results. A latest long-term trial of 12-week twice-daily IN OXT therapy failed to show any positive impact. ${ }^{4}$ Another metanalysis of eight randomized controlled trials conducted last year also showed no improvements of the social functioning. ${ }^{5}$

We suggest that further larger scale studies are needed to establish a proper role for OXT in the treatment of these symptoms. It is worth mentioning that as shortterm trials have shown us positive results in the past, it is necessary to conduct trials comparing treatments of different durations so that we can get a clear picture about the use of OXT in future therapy of the disease.
Department of Medicine, Dow Medical College, Dow University of Health Sciences, Flat no. A-303, Lateef square, Block-16, Federal b area, Karachi 75950, Pakistan

Tel +92346391 8294

Email owaisgul96@yahoo.com 


\section{Disclosure}

The authors report no conflicts of interest in this communication.

\section{References}

1. Guzel D, Yazici AB, Pek TM, et al. Atrial natriuretic peptide and posterior pituitary neurohormone changes in patients with acute schizophrenia. Neuropsychiatr Dis Treat. 2018;14:1855-1860.

2. Gibson CM, Penn DL, Smedley KL, Leserman J, Elliott T, Pedersen CA. A pilot six-week randomized controlled trial of oxytocin on social cognition and social skills in schizophrenia. Schizophr Res. 2014;156(2-3): 261-265.
3. Guastella AJ, Ward PB, Hickie IB, et al. A single dose of oxytocin nasal spray improves higher-order social cognition in schizophrenia. Schizophr Res. 2015;168(3):628-633.

4. Jarskog LF, Pedersen CA, Johnson JL, et al. A 12-week randomized controlled trial of twice-daily intranasal oxytocin for social cognitive deficits in people with schizophrenia. Schizophr Res. 2017;185:88-95.

5. Williams DR, Bürkner PC. Effects of intranasal oxytocin on symptoms of schizophrenia: A multivariate Bayesian meta-analysis. Psychoneuroendocrinology. 2017;75:141-151. 


\section{Authors' reply \\ Esra Yazici' \\ Derya Guzel² \\ Ahmet Bulent Yazici'}

'Department of Psychiatry, School of Medicine, Sakarya University, Sakarya, Turkey; ${ }^{2}$ Department of Physiology, School of Medicine, Sakarya University, Sakarya, Turkey

Correspondence: Ahmet Bulent Yazici

Department of Psychiatry, School of Medicine, Sakarya University, Korucuk Street, Sakarya 54290, Turkey

Tel +905325994988

Fax +902642552105

Email a.bulentyaz@gmail.com

\section{Dear editor}

We would like to thank Gul et al for their kind and valuable comments on our work. Briefly, our study was about the changes in levels of oxytocin (OXT), arginine-vasopressin (AVP), and atrial natriuretic peptide (ANP) in patients with acute schizophrenia and reported the following findings:

1) Concentrations of OXT were lower in patients with acute schizophrenia than in healthy controls, and there was a negative correlation between OXT levels and positive symptoms, measured on the Positive and Negative Symptom Scale, and severity, measured on the Clinical Global Impression (CGI) scale.

2) There was a positive correlation between OXT levels and functionality according to the General Assessment of Functionality scale.

3) Concentrations of AVP were significantly higher in patients with schizophrenia, and there was a negative correlation between AVP levels and CGI scores.

4) Concentrations of ANP were lower in schizophrenia patients with acute attacks but not at a significant level, and ANP levels were not correlated with clinical features. ${ }^{1}$

The molecular basis of neuropsychiatry and its impact on clinical treatments have been recent topics of interest. The etiology of schizophrenia is still not understood completely. Treatment topics, such as negative symptoms, cognitive decline, and social impairment, await further exploration with respect to etiology. The need for a better understanding of the hormonal basis of psychiatric disorders has prompted us and other researchers to investigate hormones and their roles in schizophrenia. ${ }^{2}$ Our study and others show that neurohormones, especially OXT, may have important roles in the etiology and treatment of schizophrenia. ${ }^{1,3-6}$ Previous studies found relationships between AVP changes and some symptoms of schizophrenia, but we did not obtain similar findings. ${ }^{7,8}$ Studies on AVP levels in schizophrenia patients are limited, and our findings showed that ANP levels were not significantly lower in schizophrenia patients compared to controls. ${ }^{1,9} \mathrm{Gul}$ et al are right to note that our study had a small sample size. Larger sample sizes and perhaps multicenter studies are needed. In another study of schizophrenia patients by part of our study team (with results that are being prepared for publication), OXT was associated with social cognition and ANP was associated with memory functions in schizophrenia patients. ${ }^{10}$ Schizophrenia researchers are generally focused on OXT roles as OXT deserves researchers' interest and attention. However, we think that other neurohormones, such as AVP and ANP, may also have important roles in schizophrenia and perhaps other psychiatric disorders.

We appreciate and thank Gul et al and the Editor in Chief of Neuropsychiatric Disease and Treatment for giving us the opportunity to discuss our study and receive comments.

\section{Disclosure}

The authors report no conflicts of interest in this communication.

\section{References}

1. Guzel D, Yazici AB, Pek TM, et al. Atrial natriuretic peptide and posterior pituitary neurohormone changes in patients with acute schizophrenia. Neuropsychiatr Dis Treat. 2018;14:1855-1860.

2. Kulkarni J, Gavrilidis E, Worsley R. Hormones and schizophrenia. In: Pletnikov MV, Waddington JL, editors. Handbook of Behavioral Neuroscience. Vol 23. Elsevier; 2016:463-480.

3. Churchland PS, Winkielman P. Modulating social behavior with oxytocin: how does it work? What does it mean? Horm Behav. 2012;61(3): 392-399.

4. Jobst A, Dehning S, Ruf S, et al. Oxytocin and vasopressin levels are decreased in the plasma of male schizophrenia patients. Acta Neuropsychiatr. 2014;26(6):347-355.

5. Rubin LH, Carter CS, Drogos L, Pournajafi-Nazarloo H, Sweeney JA, Maki PM. Peripheral oxytocin is associated with reduced symptom severity in schizophrenia. Schizophr Res. 2010;124(1-3):13-21.

6. Feifel D, Shilling PD, MacDonald K. A review of oxytocin's effects on the positive, negative, and cognitive domains of schizophrenia. Biol Psychiatry. 2016;79(3):222-233.

7. Rubin LH, Wehring HJ, Demyanovich H, et al. Peripheral oxytocin and vasopressin are associated with clinical symptom severity and cognitive functioning in midlife women with chronic schizophrenia. Schizophr Res. 2018;195:409-411.

8. Rubin LH, Carter CS, Bishop JR, et al. Peripheral vasopressin but not oxytocin relates to severity of acute psychosis in women with acutelyill untreated first-episode psychosis. Schizophr Res. 2013;146(1-3): $138-143$.

9. Ohsawa H, Kishimoto T, Shimayoshi N, et al. Atrial natriuretic peptide and arginine vasopressin secretion in schizophrenic patients. Acta Psychiatr Scand. 1993;88(2):130-134.

10. Mutu T, Yazici E, Guzel D, Erol E. The relationship of oxytocin, vasopressin, and atrial natriuretic peptide levels with cognitive functions in patients with schizophrenia. Outstanding Awards Brief Reports. Psychiatry Clin Psychopharmacol. 2018;28(Suppl 1):290. 
Dove Medical Press encourages responsible, free and frank academic debate. The content of the Neuropsychiatric Disease and Treatment 'letters to the editor' section does not necessarily represent the views of Dove Medical Press, its officers, agents, employees, related entities or the Neuropsychiatric Disease and Treatment editors. While all reasonable steps have been taken to confirm the content of each letter, Dove Medical Press accepts no liability in respect of the content of any letter, nor is it responsible for the content and accuracy of any letter to the editor.

\section{Publish your work in this journal}

Neuropsychiatric Disease and Treatment is an international, peerreviewed journal of clinical therapeutics and pharmacology focusing on concise rapid reporting of clinical or pre-clinical studies on a range of neuropsychiatric and neurological disorders. This journal is indexed on PubMed Central, the 'PsycINFO' database and CAS, and is the official journal of The International Neuropsychiatric Association (INA). The manuscript management system is completely online and includes a very quick and fair peer-review system, which is all easy to use. Visit http://www.dovepress.com/testimonials.php to read real quotes from published authors.

Submit your manuscript here: http://www.dovepress.com/neuropsychiatric-disease-and-treatment-journal 